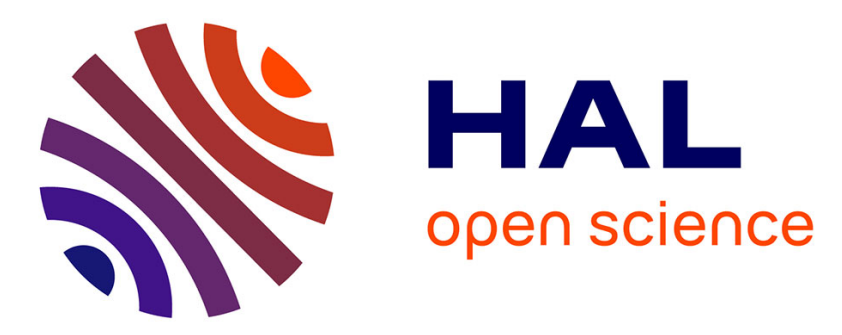

\title{
A mesoscopic model of the intermixing during nanoenergetic materials processing
}

Anne Hémeryck, M. Petrantoni, Alain Estève, C. Rossi, Mehdi

Djafari-Rouhani, Georges Landa, Daniel Estève

\section{- To cite this version:}

Anne Hémeryck, M. Petrantoni, Alain Estève, C. Rossi, Mehdi Djafari-Rouhani, et al.. A mesoscopic model of the intermixing during nanoenergetic materials processing. Journal of Physics and Chemistry of Solids, 2010, 71 (2), pp.125. 10.1016/j.jpcs.2009.07.019 hal-00609752

\section{HAL Id: hal-00609752}

\section{https://hal.science/hal-00609752}

Submitted on 20 Jul 2011

HAL is a multi-disciplinary open access archive for the deposit and dissemination of scientific research documents, whether they are published or not. The documents may come from teaching and research institutions in France or abroad, or from public or private research centers.
L'archive ouverte pluridisciplinaire HAL, est destinée au dépôt et à la diffusion de documents scientifiques de niveau recherche, publiés ou non, émanant des établissements d'enseignement et de recherche français ou étrangers, des laboratoires publics ou privés. 


\section{Author's Accepted Manuscript}

A mesoscopic model of the intermixing during nanoenergetic materials processing

A. Hémeryck, M. Petrantoni, A. Estève, C. Rossi, M. Djafari Rouhani, G. Landa, D. Estève

PII:

S0022-3697(09)00193-0

DOI: doi:10.1016/j.jpcs.2009.07.019

Reference: PCS 5908

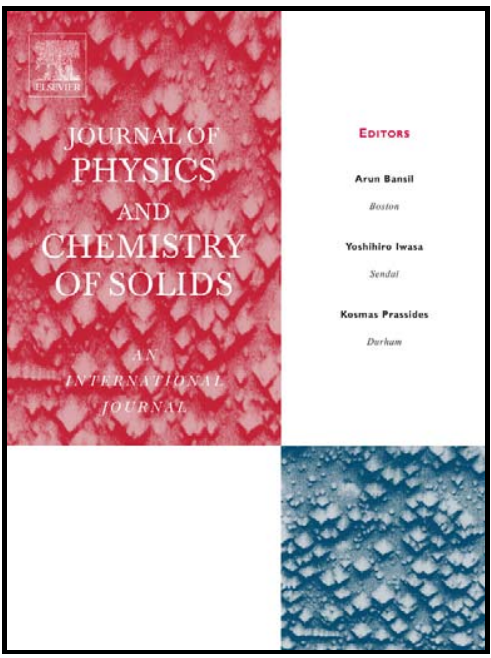

www.elsevier.com/locate/jpcs

To appear in: $\quad$ Journal of Physics and Chemistry of Solids

Received date: 5 July 2009

Accepted date: 22 July 2009

Cite this article as: A. Hémeryck, M. Petrantoni, A. Estève, C. Rossi, M. Djafari Rouhani, G. Landa and D. Estève, A mesoscopic model of the intermixing during nanoenergetic materials processing, Journal of Physics and Chemistry of Solids, doi:10.1016/j.jpcs.2009.07.019

This is a PDF file of an unedited manuscript that has been accepted for publication. As a service to our customers we are providing this early version of the manuscript. The manuscript will undergo copyediting, typesetting, and review of the resulting galley proof before it is published in its final citable form. Please note that during the production process errors may be discovered which could affect the content, and all legal disclaimers that apply to the journal pertain. 


\section{Paper reference number:}

Title of the paper: A mesoscopic model of the intermixing during nanoenergetic materials processing

\section{Corresponding Author:}

Name: Anne Hemeryck

Mailing address: CNRS ; LAAS ; 7 avenue du colonel Roche, 31077 Toulouse cedex

Tel: +33-(0)561336247 - Fax: +33-(0)561336208

e-mail address: hemeryck@laas.fr

Keywords:

Multilayers, thin films, interfaces, nanostructures, intermetallic compounds, diffusion

Table of the length of the manuscript

\begin{tabular}{|l|l|}
\hline $\begin{array}{l}\text { Words contained in the text (abstract }+ \text { list of } \\
\text { ref but not figure caption) }\end{array}$ & 3539 words \\
\hline Number of figure & $3=450$ words \\
\hline
\end{tabular}


A mesoscopic model of the intermixing during nanoenergetic materials processing

A. Hémeryck ${ }^{1,2}$, M. Petrantoni ${ }^{1,2}$, A. Estève ${ }^{1,2}$, C. Rossi $^{1,2}$, M. Djafari Rouhani ${ }^{1,2}$, G. Landa $^{1,2}$, D. Estève $e^{1,2}$

${ }^{1}$ CNRS ; LAAS ; 7 avenue du colonel Roche, F-31077 Toulouse, France

${ }^{2}$ Université de Toulouse ; UPS, INSA, INP, ISAE, LAAS ; F-31077 Toulouse, France

\begin{abstract}
A general mesoscopic model for the simulation of thin film vapor deposition applied to energetic materials, specifically bimetallic multilayers, is presented. We describe the set up of this mesoscopic simulator developed in the frame of a multiscale study by implementing $a b$ initio data into a set of differential equations. We present numerical results relative to the formation of barrier layers as a result of interdiffusion between successive bimetallic AlNi multilayers. The key role of the vacancies species created during deposition is highlighted.
\end{abstract}




\section{Introduction}

Nanostructured reactive multilayer films are typically formed by alternating chemically distinct materials [1-9] such as $\mathrm{Al} / \mathrm{Ni}$, which release heat during mixing. With the thin film vapor deposition techniques, such as Physical Vapor Deposition (PVD) [4,6,10] or Atomic Layer Deposition (ALD) [11], intimate and nearly perfect layers can be processed leading to highly reactive materials [12].

The performances of these energetic materials in terms of stability and reactivity are dependent on the composition, atomic structure, thickness and intimacy of the nanoscale layers. During deposition processes, atomic migrations give rise to an interfacial premixing layer between the two pure polycrystalline constituents [5]. This intermixed layer, in which both composition and structure are unknown, is shown to be one of the major sources of the overall loss of performance of the energetic materials. For instance, it is shown that the intermixing region has a major impact on the thermodynamic driving potential such as the degradation of the self propagating reactions and the reduction of the stored chemical energy $[5,10,13,14]$. Controlling this interface structure and its formation become crucial in order to get tailored energetic materials in terms of ignition rate and amount of released energy. Our aim in this work is to investigate how the formation of the intermixing layer can be shaped by adjusting the parameters of the deposition process.

In the following, we describe a novel mesoscopic modeling frame in which multilayer deposition is achieved allowing explicit treatment of exothermic reaction with associated dissipation and combustion phenomena. In more details, this mesoscopic model has three main characteristics which make it apart from the other existing models. First, the interfacial layer is not "hand-built" but is formed during the simulation of the deposition process. This simulator could thus be used as a pre-calculation step for a global multi-scale simulation procedure. The objective is to guide other existing approaches $[15,16]$ of the combustion 
process based on artificial "hand-built" premixing layer, in order to get a more representative interfacial premixing zone. Second, this model is set up by considering a bottom-up approach $[17,18]$ where ab initio calculations are performed in order to characterize the elementary atomic scale mechanisms (structurally and energetically) occurring during the deposition process. These mechanisms are then used as input parameters in our mesoscopic model. In this manner, the model does not rely on adjustable nor empirical parameters and is only based on theoretical considerations. For sake of brevity, the ab initio data will not be discussed in the present paper. Third, the model is original because it includes mechanisms which are environment dependent with a meso/macroscale model: each atomic reaction is driven by the local composition of the layer in which it occurs. This predictive model is able to establish a direct link between the species concentrations in each layer of the material and their relation with the composition of other layers and the processing parameters. Although the model is generic for bilayer materials, we detail, in this paper, a set of equations intended to be validated on the model system composed of a bimetallic material, i.e. an AlNi multilayer film.

\section{Methodology: Mesoscopic modeling}

\subsection{Atomic scale mechanisms}

Using ab initio calculations, we have identified eight general elementary reactions that can occur in the multilayered $\mathrm{Al} / \mathrm{Ni}$ materials: three of them are described as intra-layer reactions and the five others are inter-layer reactions. On the other hand, these reactions are qualified as: (i) "creation" like a defect formation mechanism, (ii) "exchange" between two chemically distinct atoms and (iii) "diffusion" mechanisms through the layers. We denote respectively as $\mathrm{SAl}$ and $\mathrm{SNi}$, aluminum and nickel atoms positioned on a lattice site of the $f c c$ crystals; as IAl and $\mathrm{INi}$, aluminum and nickel atoms in a non-lattice position, and as $\mathrm{V}$ a vacancy. This vacancy can be initially present in the layer, created by atomic migration between the layers or provided to the system during the deposition process. 
We detail in the following the intra-layer reactions occurring in a layer referred to as $n$, and inter-layer reactions occurring between two adjacent layers referred to as $n$ and $n \pm 1$. These elementary mechanisms are written as:

- Vacancy formation [19,20], providing a vacancy (V) and a non-lattice atoms (IAl or INi) [21] from an atom in a lattice position ( $\mathrm{SAl}$ or $\mathrm{SNi}$ ), is considered for both constituents:

$$
\begin{aligned}
& \text { SNi(n) } \leftrightarrow \text { INi(n) }+ \text { V(n) } \\
& \text { SAI(n) } \leftrightarrow \text { IAI(n) }+ \text { V(n) }
\end{aligned}
$$

This reaction is considered as possible in the model despite its large formation energy for NiAl system, estimated at roughly $8 \mathrm{eV}$ using ab initio calculations, since the model is generic and does not refer to this special case. The occurrence of this reaction is however automatically inhibited in $\mathrm{Ni}-\mathrm{Al}$ system because of its very low reaction rate.

- Exchange between two kinds of chemically different species, respectively in lattice and non-lattice positions

$$
\text { SNi(n) }+\mathbf{I A I}(n) \leftrightarrow \mathbf{I N i}(n)+\operatorname{SAl}(n)
$$

- Exchange of two crystalline species present in two adjacent layers is allowed:

$$
\operatorname{SNi}(\mathbf{n})+\operatorname{SAl}(\mathbf{n} \pm 1) \leftrightarrow \operatorname{SNi}(\mathbf{n} \pm \mathbf{1})+\operatorname{SAl}(\mathbf{n})
$$

- Two diffusion mechanisms mediated by the presence of a vacancy

$$
\begin{aligned}
& \mathrm{SNi}(\mathrm{n})+\mathrm{V}(\mathrm{n} \pm \mathbf{1}) \leftrightarrow \mathrm{SNi}(\mathrm{n} \pm \mathbf{1})+\mathrm{V}(\mathrm{n}) \\
& \mathrm{SAl}(\mathrm{n})+\mathrm{V}(\mathrm{n} \pm \mathbf{1}) \leftrightarrow \operatorname{SAl}(\mathrm{n} \pm \mathbf{1})+\mathrm{V}(\mathrm{n})
\end{aligned}
$$

- Two mechanisms relative to the diffusion of non-lattice species

$$
\operatorname{INi}(n) \leftrightarrow \operatorname{INi}(n \pm 1)
$$

$$
\operatorname{IAI}(\mathbf{n}) \leftrightarrow \operatorname{IAI}(\mathbf{n} \pm \mathbf{1})
$$


These reactions have been characterized using ab initio/Density Functional Theory. Five different systems have been considered. Two are pure $\mathrm{Al}$ and $\mathrm{Ni}$ bulk materials, one is AlNi bulk alloy and the two remaining represent $\mathrm{Al}(111)$ and $\mathrm{Ni}(111)$ surfaces. Each system consists of a supercell of 96 atoms distributed in 6 layers of 16 atoms. Periodic boundary conditions are applied in all three directions. These results are still the subject of current research and should be published soon.

\subsection{Implementation of the Chemical Rate theory}

In order to access to the temporal evolution of the system during the technological process, it is necessary to follow the concentration of each species constituting the layer. The species concentrations are noted as $[\mathbf{S N i}],[\mathbf{S A I}],[\mathbf{I N i}],[\mathbf{I A I}]$ and $[\mathbf{V}]$ for the five identified species. Two kinds of mechanisms have been distinguished:

- The "incoming molecular flux" providing species during deposition and filling in the empty layers. Ab initio calculations have shown that both atomic adsorptions of $\mathrm{Ni}$ on $\mathrm{Al}(111)$ and $\mathrm{Al}$ on $\mathrm{Ni}(111)$ result in hexagonal lattice positions $\mathrm{SNi}$ and $\mathrm{SAl}$. The adsorbed atom is placed above adjacent sub-layer bulk lattice atom. The incoming molecular flux is distributed among successive deposited layers, proportionally to the area exhibited by each layer. The adsorption mechanism which does not require any activation energy is driven by the Maxwell Boltzmann statistics in the gas phase, expressed as:

$$
\Phi_{\mathrm{gas}}=\mathrm{C} \frac{\mathbf{P}_{\mathrm{gas}} \mathbf{S}}{\sqrt{\mathbf{M}_{\mathrm{gas}} \mathbf{T}_{\mathrm{gas}}}}
$$

with $\mathrm{P}_{\text {gas }}$ the partial pressure of the considered gas $(\mathrm{Pa}), \mathrm{S}$ the surface of the elementary cell (considering Al or Ni lattice parameter) $\left(\mathrm{m}^{2}\right), \mathrm{M}_{\text {gas }}$ the molar mass of the gas $\left(\mathrm{kg} \cdot \mathrm{mol}^{-1}\right), \mathrm{T}_{\text {gas }}$ the gas temperature $(\mathrm{K})$, and $\mathrm{C}$ a constant. In this manner, the pressure and the temperature of the incoming gas are introduced as in a real processing experiment. 
- For all others implemented mechanisms, the performed ab initio calculations reveal that an activation energy is required. This energetic barrier determines the probability of occurrence of a given event that depends also on the temperature. This is implemented in the model using the Arrhenius law which leads to the reaction constants $\mathbf{k}_{\mathbf{i}}$ :

$$
\mathbf{k}_{\mathbf{i}}=\boldsymbol{v} \times \mathbf{e}^{\frac{-\mathbf{A}_{\mathrm{i}}}{\mathbf{R}_{\mathrm{g}} \mathbf{T}_{\text {layer }}}}
$$

With $\mathbf{A}_{\mathbf{i}}$ the activation energy of the mechanism $i\left(\mathrm{~J}_{\mathrm{mol}}{ }^{-1}\right), \mathrm{R}_{\mathrm{g}}$ the ideal gas constant $\left(8.31 \mathrm{~J} \cdot \mathrm{mol}^{-1} \cdot \mathrm{K}^{-1}\right.$ ) and $\mathbf{T}_{\text {layer }}$ the time dependent layer temperature $(\mathrm{K}) . \mathrm{v}$ is a dynamic prefactor corresponding to the Debye frequency. $v$ represents an attempt frequency of jump and is estimated at $10^{13} \mathrm{~s}^{-1}$.

The effects of phase changes in the film such as alloy formation due to the melting of the reactants or products formation are neglected.

\subsection{Implementation of heat exchange}

The chemical reactions occurring in the energetic materials are highly exothermic and produce heat during mixing. This heat release is also present during the deposition process due to atomic migration leading to a structural rearrangement and to the formation of the premixing zone. In order to build a realistic and accurate model dedicated to the energetic materials, the temperature variations in the multilayer films have to be taken into account. We assume a uniform time dependent temperature throughout the multilayer film. This approximation is mainly justified by the small thickness of the multilayer films, of the order of few nm, compared to the thickness of the silicon substrate, of the order of $100 \mu \mathrm{m}$. Spatial variations of the temperature, if present, occur only in the silicon substrate. They could be taken into account via heat conduction in the silicon substrate film. However, these spatial 
variations are not implemented in this first version of the model, since we consider only mechanisms where the atomic species diffusivities are smaller than diffusivity. In this model, temperature variations result from exothermic reactions and the convective and radiative heat losses on the wafer surfaces. Concerning the radiative heat losses, the multilayer film is approximated as a black-body radiating with unit emissivity, which ideally exchanges with unbounded surroundings at ambient temperature.

Also, in the present version of the model, physical properties such as thermal conductivity, density and heat capacity are assumed to be independent of the temperature and of the layer composition. In a future version of the model, the temperature dependence of these parameters can be easily taken into account, if necessary. Considering the above points, the temporal evolution of the temperature can be written as:

$\rho_{\mathrm{Si}} \mathrm{c}_{\mathrm{Si}} \mathrm{e}_{\mathrm{Si}} \frac{\mathrm{dT}}{\mathrm{dt}}=\sum_{\mathrm{i}} \mathrm{Q}_{\mathrm{i}}-\mathrm{h}\left(\mathrm{T}-\mathrm{T}_{0}\right)-\sigma\left(\mathrm{T}^{4}-\mathrm{T}_{0}^{4}\right)$

With $\rho_{\mathrm{Si}}$ the silicon density $\left(2330 \mathrm{~kg} \cdot \mathrm{m}^{-3}\right), \mathrm{c}_{\mathrm{Si}}$ the silicon heat capacity $\left(700 \mathrm{~J} \cdot \mathrm{kg}^{-1} \cdot \mathrm{K}^{-1}\right), \mathbf{h}$ the convective heat exchange coefficient, $\mathbf{e}_{\mathrm{Si}}$ the silicon substrate thickness (m), $\mathbf{T}_{\mathrm{Si}}$ is the temperature of the silicon substrate, $\sigma$ the Stefan-Boltzmann's constant $\left(5.67 \times 10^{-8} \mathrm{~W} \cdot \mathrm{m}^{-2} \cdot \mathrm{K}^{-}\right.$ $\left.{ }^{4}\right), \mathbf{T}_{\mathbf{0}}$ the ambient temperature and $\mathbf{Q}_{\mathbf{i}}$ the heat released by each exothermic reaction during the time interval dt. This last parameter is environment dependent (Section 2.4).

The model is therefore composed of $5 n+1$ differential equations for the description of the concentration variations for a material with $\mathbf{n}$ layers: five equations for the five species in each layer and one equation for the uniform temperature.

\subsection{Implementation of the environment dependent reactions}

The originality of the model is that the activation barriers $\mathbf{A}_{\mathbf{i}}$ are environment dependent: they explicitly depend on the composition of each layer and account for the heat production 
noted as $\mathbf{Q}_{\mathbf{i}}$. In order to implement this environmental dependence in the model, the total energy is assumed to be the sum of an electronic term and nearest neighbor pair interactions. The energy of an atom of type $\mathrm{J}$ can then be written as: $\mathbf{E}(\mathbf{J})=\mathbf{E}_{\mathbf{0}}(\mathbf{J})+\mathbf{n}_{\mathrm{j}} \varepsilon_{\mathrm{jj}}+\mathbf{n}_{\mathrm{k}} \varepsilon_{\mathrm{jk}}$

Where $\mathbf{E}_{\mathbf{0}}$ corresponds to the electronic term, $\mathbf{n}_{\mathbf{j}}$ and $\mathbf{n}_{\mathbf{k}}$ are the ratios of species $\mathbf{j}$ and $\mathbf{k}$ in the layer, and $\boldsymbol{\varepsilon}_{\mathrm{jj}}$ and $\boldsymbol{\varepsilon}_{\mathrm{jk}}$ are the pair interaction energies between two nearest neighbors, of the same type or of different types, respectively. The ratios $\mathbf{n}_{\mathbf{j}}$ and $\mathbf{n}_{\mathbf{k}}$ of species in the layer are expressed as $\mathrm{n}_{\mathrm{j}}=\frac{[\mathrm{J}]}{[\mathrm{J}]+[\mathrm{K}]+[\mathrm{V}]}$ and $\mathrm{n}_{\mathrm{k}}=\frac{[\mathrm{K}]}{[\mathrm{J}]+[\mathrm{K}]+[\mathrm{V}]}$.

Where $[\mathrm{J}],[\mathrm{K}]$ and $[\mathrm{V}]$ respectively stand for the concentrations of $\mathrm{J}$ and $\mathrm{K}$ species, and for the vacancy concentration. We have assumed that vacancies may be present in the layers as a result of kinetic effects and the lattice mismatch between the two materials.

The energy values for the starting position, the final configuration and the transition state are evaluated at each step of the simulation, for all possible elementary reactions and for each layer in the film. Using these calculated energies (Figure 1), the activation energies $\mathbf{A}_{\mathbf{i}}$ as well as the released heat $\mathbf{Q}_{\mathbf{i}}$ for both the direct and the reverse reactions and for each elementary mechanism can be determined. In this way, the knowledge of only three energetic parameters dependent on the composition of each layer, allows us to address the desired environmental dependence.

\section{Preliminary results}

In the following, we present preliminary results concerning the $\mathrm{Ni} / \mathrm{Al}$ multilayer bimetallic films deposited on silicon substrates. The aim of the simulation is a first validation of the model through a simple system for which experimental and theoretical data are available in the literature. Also, the technology process conditions have been simplified as much as 
possible. For instance, the temperature has not only been considered as uniform over the whole sample, but also constant in time and equal to the ambient temperature. This approximation is justified in cases where the silicon substrate is strongly cooled during metal deposition.

In all following simulations, the ambient temperature is kept fixed at $298 \mathrm{~K}$. The incoming gas is at $350 \mathrm{~K}$ under a pressure of $0.005 \mathrm{~Pa}$. We mainly focus on the role of vacancies present at the interface between the two nanolayers. Our objective is to understand to what extent their presence is necessary for the formation of an intermixed zone between the pure nanolayers. In a first set of simulation runs, we successively investigate the deposition of $\mathrm{Ni} /$ perfect $\mathrm{Al}(111)$ substrates and of $\mathrm{Al} /$ perfect $\mathrm{Ni}(111)$ substrates, to get insight on both interfaces. However, in these preliminary simulations, we have not examined multilayer deposition. All simulations of this set run for $3 \mathrm{~s}$ with $\mathbf{e}_{\mathrm{Si}}=\mathbf{1} \boldsymbol{\mu m}$.

The atomic pair interaction energies have been estimated via $a b$ initio calculations. Five periodic structures of pure $\mathrm{Al}$, of pure $\mathrm{Ni}$ and of AlNi alloy have been considered using a large spectrum of situations: vacancies, interstitials, Frenkel pairs, atom/surface interactions... The values for the electronic energies and the pair interaction energies have been estimated by fitting the total energies to the corresponding values obtained using DFT, in all considered cases. The best fit is observed for: $\mathbf{E}_{\mathbf{0}}(\mathbf{N i})=-\mathbf{3 . 4 1 5 5 e V}, \mathbf{E}_{\mathbf{0}}(\mathbf{A l})=-\mathbf{2 . 8 5 3 3} \mathrm{eV}$, $\varepsilon_{\mathrm{SNi}-\mathrm{SNi}}=-0.5225 \mathrm{eV}, \boldsymbol{\varepsilon}_{\mathrm{SAl}-\mathrm{SAl}}=-0.2214 \mathrm{eV}, \boldsymbol{\varepsilon}_{\mathrm{SAl}-\mathrm{SNi}}=-0.7452 \mathrm{eV}, \varepsilon_{\mathrm{INi}-\mathrm{SNi}}=-0.2191 \mathrm{eV}$, $\varepsilon_{\mathrm{INi}-\mathrm{SAl}}=-0.5695 \mathrm{eV}, \varepsilon_{\mathrm{IAI}-\mathrm{SAl}}=-0.0507 \mathrm{eV}$ and $\varepsilon_{\mathrm{IAI}-\mathrm{SNi}}=-0.1981 \mathrm{eV}$. Interactions between two non-lattice positions (INi-INi, IAl-IAl, IAl-INi) have not been considered in this first version of the model, due to the low probability of finding two interstitials close to each other. For both cases, deposition of $\mathrm{Ni}$ or $\mathrm{Al}$, we consider that the first material is already deposited so that the starting point of the simulation concerns the deposition of the second material. Figure 2 a represents a schematic view of the starting configuration and the partially covered 
layers during the process. Figure $2 \mathrm{~b}$ shows the actual coverage of the successive deposited layers versus time. No vacancy supply has been introduced in this first set of simulations. At the end of the simulation, the compositions of the deposited layers and of the substrate layers are very close to the pure constituents. This reveals that during the deposition of $\mathrm{Al} / \mathrm{Ni}(111)$ or $\mathrm{Ni} / \mathrm{Al}(111)$, with a growing multilayer film maintained at ambient temperature, no interfacial mixing can be obtained if no vacancy is provided during the deposition process. In fact, the considered atomic scale reactions are very difficult to occur in these metallic materials at low temperatures, as expected from DFT results.

For instance, if we focus on the exchange between two atoms, SNi or SAl, described in the reaction R.IV, the exchange of SNi located in a pure nickel layer with a SAl located in a pure aluminum layer, will require energy barriers up to $5 \mathrm{eV}$. This has been determined using $a b$ initio calculations where the theoretical minimum energy pathway is characterized by a multistep reaction involving several non-lattice positions for the migrating species and its neighboring atoms.

Despite the small intermixing occurring during room temperature simulations, we can still observe two general trends, in agreement with ab initio calculations performed to determine the adsorption pathways. The first concerns the heat loss during deposition which is larger when $\mathrm{Al}$ is deposited on a Ni substrate. The second is that the intermixing is asymmetric: Ni atoms penetrate easily the $\mathrm{Al}(111)$ substrate, while $\mathrm{Al}$ remains on $\mathrm{Ni}(111)$ surface. The theoretical pathways obtained show that only a $0.06 \mathrm{eV}$ activation barrier allows the penetration of the $\mathrm{Ni}$ atom into the first $\mathrm{Al}(111)$ sub-layer. The activation barrier for the migration of the $\mathrm{Ni}$ atom into the second $\mathrm{Al}(111)$ sub-layer is of $1.2 \mathrm{eV}$, in the range of bulk migration energies. Looking at the $\mathrm{Al}$ on $\mathrm{Ni}(111)$ case, the activation barrier for the $\mathrm{Al}$ atom to penetrate the first $\mathrm{Ni}(111)$ sub-layer amounts to $1.56 \mathrm{eV}$, much higher than the previous value. This reaction is practically forbidden at room temperature. Therefore, the intermixed zone, for room temperature processes, results at the $\mathrm{Ni} / \mathrm{Al}(111)$ interface rather than at the 
$\mathrm{Al} / \mathrm{Ni}(111)$ interface. This asymmetry shows that tuning experimental conditions is a key for the optimization of the multilayer films, particularly in terms of formation of intermixed zones. These conditions might eventually be different for the two, Ni and Al, deposition processes.

In a second set of runs, the simulations are performed by considering a perfect material composed of four Ni monolayers in direct contact with four Al monolayers and a film temperature maintained at $298 \mathrm{~K}$. These simulations run last for $1 \mathrm{~s}$ with no incoming gas flux. When an artificial amount of vacancies, $10 \%$ here, is introduced in the interfacial monolayer between the two pure constituents, the mixing reactions are activated, even at room temperature. Here, we wish to emphasize that the vacancy presence in the interfacial layer will be key in the mixing taking place during the vapor deposition as the vacancies favor the mixing at the interface. Indeed, activation barriers, as calculated using the three states (Figure 1), are strongly reduced in the presence of vacancies.

\section{Conclusion}

During multilayer deposition processes, an intermixing reaction inevitably occurs between the two constituents leading to the formation of a premixed zone which separates pure layers of the films. This paper presents a first attempt to set up a model for the deposition process and the structural arrangement during the deposition, based on a multi-scale approach combining chemical rate theory and $a b$ initio results. In these preliminary results, a first trend appears: the diffusion of $\mathrm{Ni}$ species seems to be easier across the bulk compared to the Al species diffusion. The key role of vacancies species provided to the system during the deposition process is also highlighted. We reveal that if no vacancy supply is provided during deposition process, for multilayer films maintained at ambient temperature, it is tricky to form an interfacial premixing layer due to the high activation barriers required to allow atomic reactions. We have shown that, in order to develop a realistic model of the deposition process, 
it is necessary to investigate and implement the mechanisms of supply of vacancies to the interfacial region. As a result of the preliminary results discussed in this paper, future work includes an accurate and realistic rate of vacancies supply during deposition process. Beyond these developments, the model presented here could be coupled to other existing modeling approaches as they mainly focus on the heat loss phenomena due to the intermixing layer, or on the combustion process. These models, starting usually from empirical premixed layers, can use our approach to define process dependent initial configurations.

\section{List of references}

[1] K. Zhang, C. Rossi, M. Petrantoni and N. Mauran, J. Microelectromechanical Systems 17 (2008) 832

[2] A.S. Rogachev, Russ. Chem. Rev. 77 (2008) 21

[3] J. Wang, E. Besnoin, O.M. Knio and T. P. Weihs, J. Appl. Phys. 97 (2005) 114307

[4] K.J. Blobaum, M.E. Reiss, J.M. Plitzko Lawrence and T. P. Weihs, J. Appl. Phys. 94 (2003) 2915

6 [5] J.A. Floro, J. Vac. Sci. Technol. A 4 (1986) 631

[6] M.G. Brookes, P.J. Kelly and R.D. Arnell, Surface and Coatings Technology 177-178 (2004) 518

[7] J.-C. Gachon, A.S. Rogachev, H.E. Grigoryan, E.V. Illarionova, J.-J. Kuntz, D.Yu. Kovalev, A.N. Nosyrev, N.V. Sachkova and P.A. Tsygankov, Acta Mater. 53 (2005) 1225

[8] A. S. Rogachev, A. E. Grigoryan, E. V. Illarionova, I. G. Kanel', A. G. Merzhanov, A. N. Nosyrev, N. V. Sachkova, V. I. Khvesyuk, and P. A. Tsygankov, Combust. Explosion and Shock Waves 40 (2004) 166

11 [9] H. Wei, X. Sun, Q. Zheng, H. Guan and Z. Hu, Acta Mater. 52 (2004) 2645

[10] A.J. Gavens, D. van Heerden, A.B. Mann, M.E. Reiss and T.P. Weihs, J. Appl. Phys. 97 (2000) 1255

[11] J.D. Ferguson, K.J. Buechler, A.W. Weimer and S.M. George, Powder Technol. 156 (2005) 154

[12] C. Rossi, K. Zhang, D. Estève, P. Alphonse, P. Tailhades and C. Vahlas, J. Microelectromechanical Systems 16 (2007) 919 
[13] S. Jayaraman, A.B. Mann, M.E. Reiss, T.P. Weihs and O.M. Knio, Combustion and Flame 124 (2001) 178

[14] A.B. Mann, A.J. Gavens, M.E. Reiss, D. van Heerden, Bao, G. and T.P. Weihs, J. Appl. Phys. 82 (1997) 1178

[15] S. Jayaraman, O.M. Knio, A.B. Mann and T. P. Weihs, J. Appl. Phys. 86 (1999) 800

[16] S. Zhao, T.C. Germann and A. Strachan, Phys. Rev. B 76 (2007) 104105

[17] A. Hémeryck, A. Estève, N. Richard, M. Djafari Rouhani and G. Landa, Surf. Sci. 603 (2009) 2132

[18] G. Mazaleyrat, A. Estève, L. Jeloaica and M. Djafari Rouhani, Comput. Mat. Sci. 33 (2005) 74

[19] K.A. Marino, E.A. Carter, Acta Mater. 56 (2008) 3502

[20] E.H. Megchiche, S. Pérusin, J.-C. Barthelat and C. Mijoule, Phys. Rev B 74 (2006) 064111

[21] C. Kim and Y.-C. Chung, Jpn J. Appl. Phys. 44 (2005) 5700 


\section{Figures caption}

Figure 1: Schematic view of an elementary chemical reaction exhibiting the three energy levels: $\mathbf{E}_{\mathbf{I}}, \mathbf{E}_{\mathbf{F}}$ and $\mathbf{E}_{\mathbf{T}}$, used for the calculation of thermodynamic ( $\left.\mathbf{Q}\right)$ and $\operatorname{kinetic}(\mathbf{A})$ parameters.

Figure 2: (a) Schematic views of the starting configurations of the multilayer films before deposition (left) and during deposition (right), (b) Evolution of the successive layers coverage versus time. 


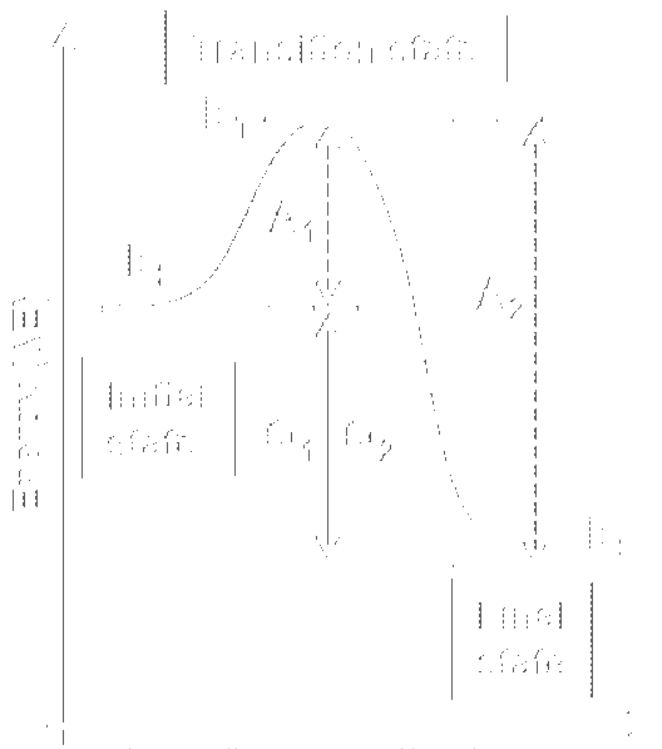

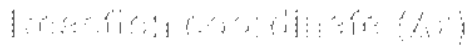

Figure 1 
(a)

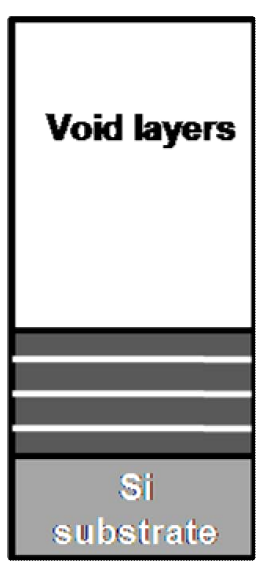

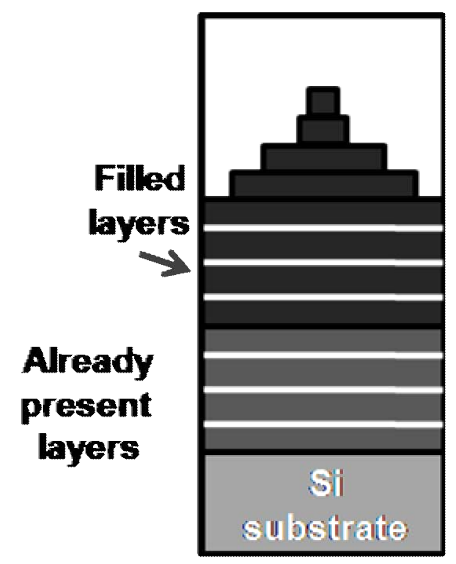

(b)

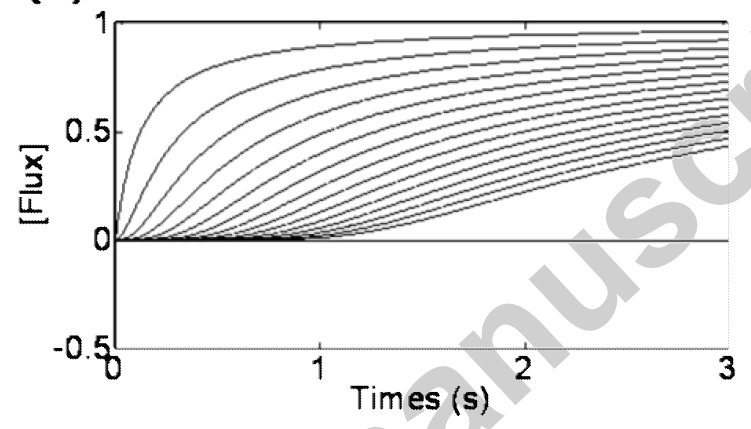

Figure 2 


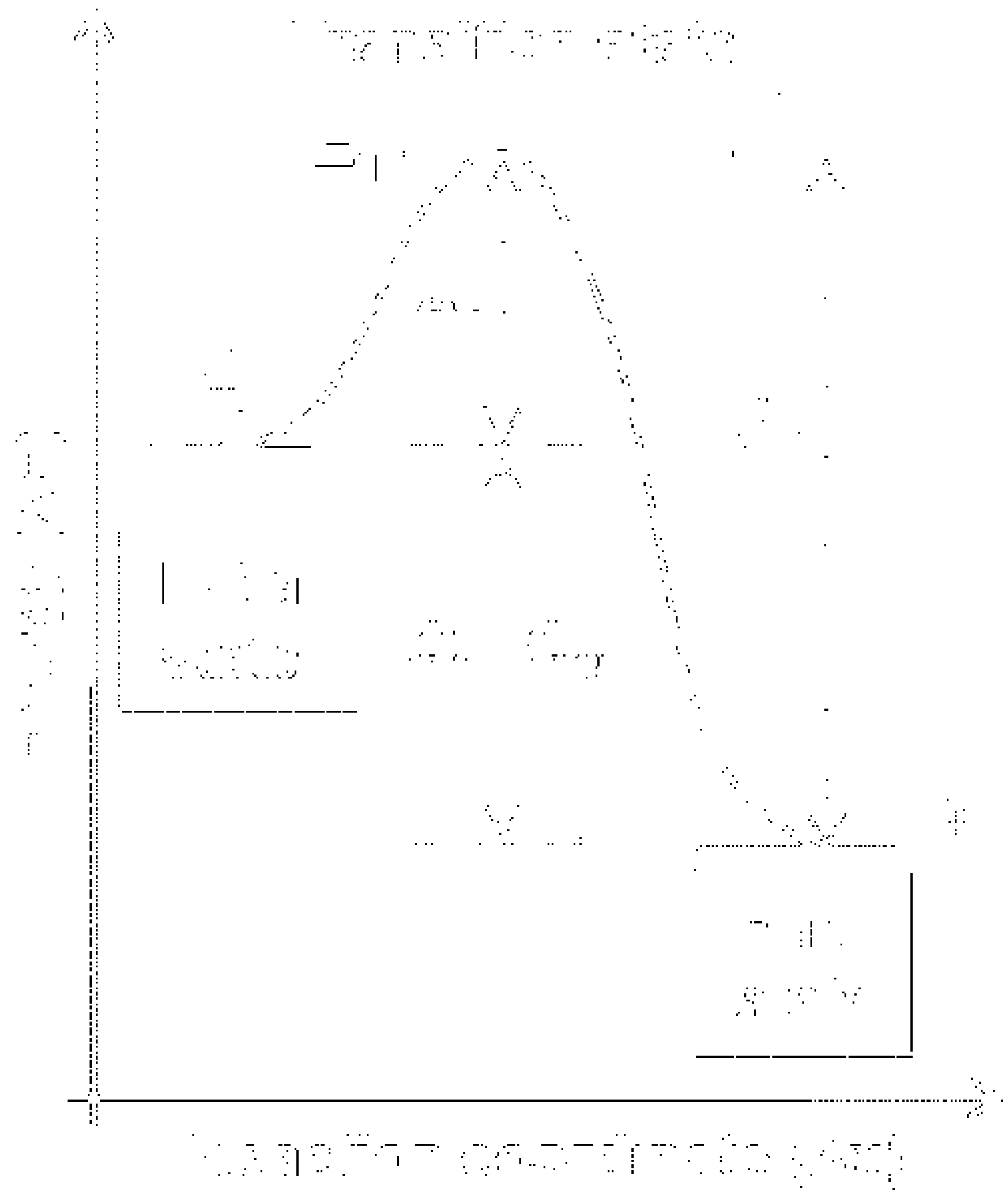


